\title{
Expression of a taste aversion conditioned with an odor-taste compound: Overshadowing is relatively weak in weanlings and decreases over a retention interval in adults
}

\author{
PHILIPP J. KRAEMER, NANCY A. LARIVIERE, and NORMAN E. SPEAR \\ State University of New York at Binghamton, Binghamton, New York
}

\begin{abstract}
Adult rats were injected with lithium chloride $(\mathrm{LiCl})$ after consumption of a novel flavor (chocolate milk) that either was or was not presented together with a novel ambient odor (banana) as a compound conditioned stimulus (CS). In Experiment 1, the adults' consumption of the flavor $24 \mathrm{~h}$ after conditioning was compared with that of weanling rats given the same conditioning treatment on Postnatal Day 21. The results confirmed previous indications that the reduction in aversion observed for adults conditioned with the compound CS (overshadowing) was weak or nonexistent in weanlings. After a longer retention interval (21 days), there was no evidence of overshadowing in adults despite maintained retention of the basic conditioned aversion. In Experiment 2 this decrease in overshadowing after a long retention interval was replicated with adult animals and extended to a different method of testing. The form of the effect was the same as in Experiment 1: The decrease in overshadowing occurred over the retention interval without loss in retention of the basic taste aversion; the decrease in overshadowing was a consequence of an increase in the flavor aversion displayed by animals conditioned with the compound CS. The impaired flavor aversion (i.e., the overshadowing) observed shortly after conditioning apparently was due to factors associated with memory retrieval, rather than to reduced attentional or associative strength.
\end{abstract}

Recent studies have shown that the learning of multipleevent episodes is more complex than was once thought. Many of the early studies on conditioning with compound stimuli found evidence of overshadowing; a strong conditioned response would appear to one of the stimulus elements, with little or no responding to the other element (Pavlov, 1927; Sutherland \& Mackintosh, 1971). It has been proposed that the more salient element overshadows the less salient element to decrease conditioning of the latter through learning or attentional mechanisms, but with the ultimate result that a weaker memory is stored to represent its conditioning (Mackintosh, 1975; Rescorla \& Wagner, 1972; Sutherland \& Mackintosh, 1971). This reasonable explanation seems to have been overpowered by the complexity of the facts.

The standard interpretation of overshadowing has assumed that the reduced responding to the overshadowed element represents an acquisition deficit (Rescorla \& Wagner, 1972; Sutherland \& Mackintosh, 1971). It has been shown recently, however, that postconditioning experiences can enhance responding to stimulus elements presumed to have acquired little if any associative strength

The authors would like to thank Norman G. Richter and Teri Tanenhaus for their assistance. The present research was supported by a grant from the National Institute of Mental Health (1 RO1 MH35219) to Norman E. Spear. Address correspondence to Norman E. Spear, Center for Developmental Psychobiology, Department of Psychology, SUNY Binghamton, Binghamton, NY 13901. during original conditioning (Kaufman \& Bolles, 1981; Matzel, Schachtman, \& Miller, 1985). These studies suggest the possibility that overshadowing represents a retrieval effect, rather than an acquisition deficit (Miller, Kasprow, \& Schachtman, 1986; Spear, 1981). A similar interpretation of generalized latent inhibition with conditioned taste aversions has also been suggested (Kraemer \& Roberts, 1984). We therefore determined to test whether performance by adult rats conditioned with odortaste compounds would be affected by a lengthy retention interval, as has been found with latent inhibition (Kraemer \& Roberts, 1984). In Experiment 1 we tested taste aversions 1 or 21 days after adult rats had been conditioned with taste alone or with an odor-taste compound. Control animals were given a taste-saline pairing.

As a further factual difficulty for the early interpretations of overshadowing, more recent experiments have shown that more salient stimuli can, under some conditions, potentiate rather than overshadow conditioning to less salient stimuli (Durlach \& Rescorla, 1980; Lett, 1980; Rusiniak, Hankins, Garcia, \& Brett, 1979). Much of the recent interest in potentiation has involved the study of drug-induced aversions conditioned with odor-taste compounds. The majority of these studies have concentrated on the odor component, and the results have been mixed. Some studies have reported potentiation of odor aversions by flavors (Durlach \& Rescorla, 1980; Rusiniak et al., 1979; Rusiniak, Palmerino, \& Garcia, 1982), but others 
have found odors to be overshadowed by flavors (Bouton \& Whiting, 1982; Mikulka, Pitts, \& Philput, 1982). In studies that have examined conditioning to the taste component, the results have also been equivocal. For example, Westbrook, Homewood, Horn, and Clarke (1983) found that odor attenuated a taste aversion (overshadowing), but Peterson, Valliere, Misanin, and Hinderliter (1985) found that odor strengthened a taste aversion (potentiation).

Peterson et al.'s (1985) study is also important from an ontogenetic perspective. They found that flavor aversions were strengthened by the presence of an odor in young adults, but not in weanlings. This age-related interaction contrasts with the ontogenetic differences reported in several other experiments under somewhat different circumstances.

In comparison with similar-aged adults in these other studies, rats conditioned as preweanlings ( 16 to 18 days postnatal) have seemed regularly to show either less overshadowing or more potentiation (Caza, 1984; Kucharski \& Spear, 1985; Spear \& Kucharski, 1984a, 1984b). With a conditioned stimulus (CS) compound of an odor and a visual stimulus, Caza and Kucharski (cited in Spear \& Kucharski, 1984a) found less overshadowing among preweanlings than among adults, but no significant potentiation in either age group. With a compound consisting of two flavors, Kucharski and Spear (1985) found that in some circumstances (e.g., simultaneous presentation of both flavors in compound) the preweanlings showed substantial potentiation but the adults showed weak or no potentiation (depending on experimental treatment), whereas in other circumstances (e.g., sequential presentation of two CS elements), the adults showed overshadowing but the infants showed neither potentiation nor overshadowing. Spear and Kucharski (1984b) reported an experiment conducted in collaboration with Caza in which ambient odor had a borderline potentiation effect with preweanlings in the conditioning of an aversion to a flavor, whereas the same ambient odor tended to produce overshadowing in the flavor conditioning for adults. Finally, a more recent experiment by Hinderliter and Misanin (1986) confirmed that greater potentiation occurred among weanlings than among adult rats when flavor conditioning was accompanied by the simultaneous presence of an odor.

Experiment 1 examined the effect of ambient odor on conditioning of a taste aversion among rats of weaning age and among young adults. This experiment was like that of Peterson et al. (1985) (but different from those of Kucharski and Spear, 1985, and Spear and Kucharski, $1984 \mathrm{~b}$ ) in using animals that had been weaned before conditioning, but it was more similar to those of Kucharski and Spear than to that of Peterson et al. in terms of the absolute age of these weanlings. We therefore performed Experiment 1 to assess the generality of the contrary effect with weanlings reported by Peterson et al., as well as to test the effect of retention interval on overshadowing in adults.

\section{EXPERIMENT 1}

\section{Method}

Subjects. Forty-eight adult $(n=8)$ and 36 weanling $(n=12)$ Sprague-Dawley rats, of both sexes, served as subjects. The adults, which ranged from 60 to 90 days of age, were housed in standard wire-mesh hanging cages. The weanlings were group-housed in plastic maternity cages when weaned at Postnatal Day 19, and were conditioned at Postnatal Day 21. All animals were housed in a climate-controlled vivarium, maintained on a 16 -h on $/ 8$-h off light/dark cycle. All testing occurred during the light portion of the cycle. The adults were placed on a 23.5 -h water deprivation schedule 7 days prior to conditioning. The weanlings were placed on a 23.5-h water deprivation schedule when weaned on Postnatal Day 19. Both weanlings and adults were given a single drinking adaptation session in which they were allowed $30 \mathrm{~min}$ access to tap water in the test room the day before conditioning.

Apparatus. Conditioning and testing occurred in wire-mesh hanging cages, located in a room away from the vivarium. Liquids were dispensed at room temperature in graduated cylinders fitted with metal spouts, which were attached to the front of each test cage. The taste stimulus consisted of a $50 \%(\mathrm{v} / \mathrm{v})$ solution of homogenized chocolate milk and water. The odorant consisted of $2 \mathrm{cc}$ of banana extract (Virginia Dare) placed on sheets of paper below each test cage. A ventilation fan and air duct filtered odors from the test room. Animals in the taste-alone groups were conditioned before the odorant was added to the room for the conditioning of the compoundstimulus groups.

Procedure. The weanling rats were randomly divided into three groups and the adults into two sets of three groups each. Each set of three groups included the following treatments on the conditioning day: Subjects in Group $\mathrm{T}$ (taste) received $\mathbf{3 0} \mathrm{min}$ exposure to the taste followed immediately by a $1 \%$ body-weight i.p. injection of $.3 \mathrm{M} \mathrm{LiCl}$; subjects in Group OT (odor + taste) were given $30 \mathrm{~min}$ exposure to an odor-taste compound followed by injection of $\mathrm{LiCl}$; and subjects in Group $\mathrm{C}$ (control) received the taste paired with injection of $.89 \% \mathrm{NaCl}$. The weanlings and one set of the adult groups were returned to their home cages immediately following injection of $\mathrm{LiCl}$ or saline, and were tested $24 \mathrm{~h}$ later (Groups T-1, OT-1, and C-1). The other three adult groups were treated the same except that they were tested 21 days after conditioning (Groups T21 , OT-21, and C-21). Testing involved $30 \mathrm{~min}$ access to the chocolate milk solution. The dependent measure was the amount of chocolate milk consumed during the test period. All individual group comparisons were evaluated with a Fisher test (Keppel, 1982), and all statistical differences were considered significant at the .05 level.

\section{Results and Discussion}

Consumption during conditioning did not differ significantly among the weanling groups or the adult groups. The mean consumption for adult Groups T, OT, and C was $17.8,17.8$, and $19.0 \mathrm{ml}$, respectively. The mean consumption for weanling Groups T, OT, and C was 2.6, 3.6 , and $3.4 \mathrm{ml}$, respectively. The mean amount of chocolate milk consumed by each of the three groups of weanlings during the test session is presented in Figure 1. It can be seen that both Group T and Group OT show evidence of acquired aversions, relative to Group $\mathrm{C}$, and aversion strength appears to be nearly equivalent in these two groups. A one-way analysis of variance indicated that consumption did differ significantly among the three groups $[F(2,33)=29.7]$, and individual group comparisons revealed that Groups $\mathrm{T}$ and $\mathrm{OT}$ consumed equivalent amounts and drank significantly less than did 


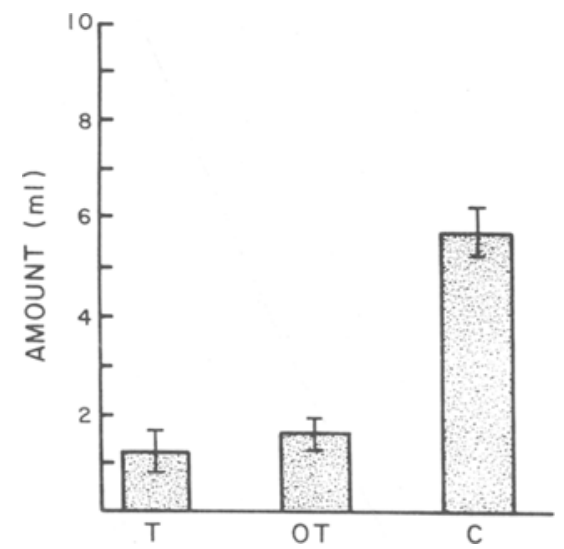

Figure 1. Amount of chocolate milk consumed by weanlings in Experiment 1.

Group C. Thus neither overshadowing nor potentiation was found with the weanlings.

The mean amount of chocolate milk consumed by each of the six adult groups during testing is presented in Figure 2. A significant conditioning experience $\times$ retention interval interaction was obtained $[F(2,42)=4.27]$. Simple main-effects analyses and individual group comparisons indicated that after the 1-day retention interval Group C drank significantly more than Group OT, which drank significantly more than Group $T$. This verified that after the 1-day interval, overshadowing occurred for the adults. After the 21-day retention interval, however, Group C drank significantly more than Groups OT and $\mathrm{T}$, which drank equivalent amounts. Additional analyses confirmed that Groups C-1 and C-21 drank equivalent amounts, as did Groups T-1 and T-21. In contrast, Group OT-1 drank significantly more than group OT-21. The overshadowing observed 1 day after conditioning was not present 21 days after conditioning. Substantial conditioning remained after this longer interval for all conditioned adults. Overshadowing dissipated with time.
Comparisons of the adults and weanlings shortly after conditioning suggest that overshadowing is a stronger effect among the older animals, which confirms the trends shown by several previous experiments. The presence of an odor had no effect on the magnitude of the weanlings' conditioned taste aversion, whereas the presence of an odor during conditioning weakened the adults' taste aversion. These ontogenetic differences in the effects of odorflavor conditioning replicate the effects summarized by Spear and Kucharski (1984a, 1984b).

For the purpose of understanding overshadowing in general, the more significant finding may be the decrease in overshadowing observed for adults after a long retention interval. This implies that overshadowing is a transient, rather than permanent, effect and suggests that it may affect memory retrieval, rather than initial storage of the memory. The generality of this effect was tested further in Experiment 2.

\section{EXPERIMENT 2}

In this experiment we tested compound conditioning in adults as a function of retention interval, to test the apparent decrease in overshadowing observed after a long retention interval. A two-bottle preference test was used to assess the generality of this effect.

\section{Method}

In this experiment we tested 48 adult rats of both sexes, of the same description as those in Experiment 1. They were randomly assigned to the three conditioning treatments: taste $+\mathrm{LiCl}(\mathrm{T})$, odor-taste $+\mathrm{LiCl}(\mathrm{OT})$, and taste + saline (C). Half of the animals in each of the three conditioning groups were tested after a 1-day interval, and the remaining animals were tested after a 21-day interval. The general procedure used in Experiment 1 was again followed, with the exception that testing involved $30 \mathrm{~min}$ exposure to two bottles, one containing tap water and the other chocolate milk. The left/right spatial arrangement of the bottles was varied randomly across subjects. The dependent measure was the percentage of chocolate milk consumed during the test session relative to total fluid consumed during this period.

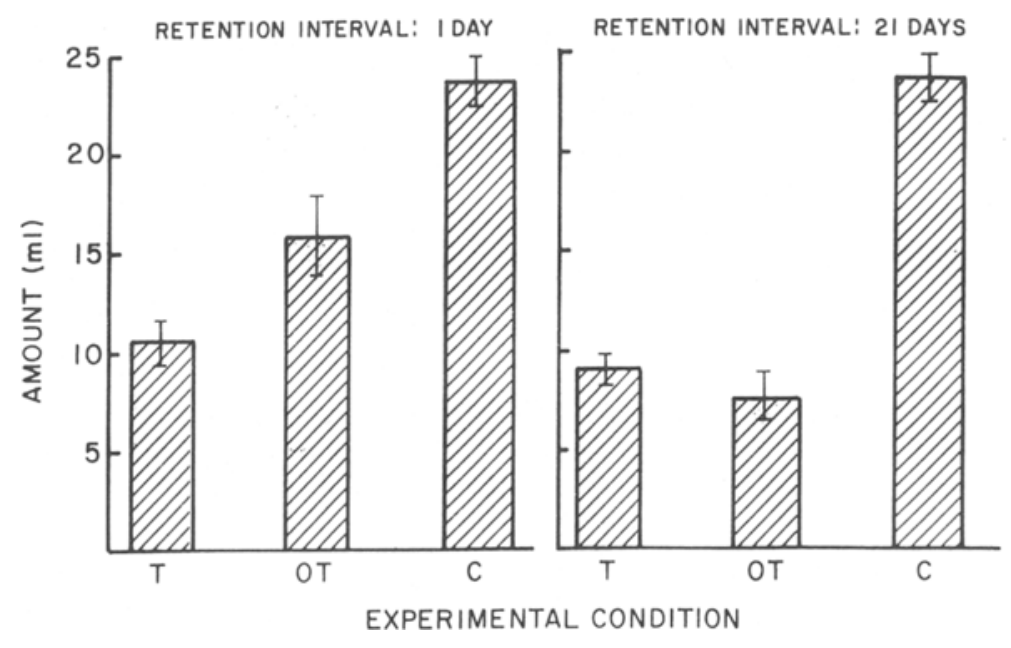

Figure 2. Amount of chocolate milk consumed by adults after a 1-day or 21-day retention interval in Experiment 1. 


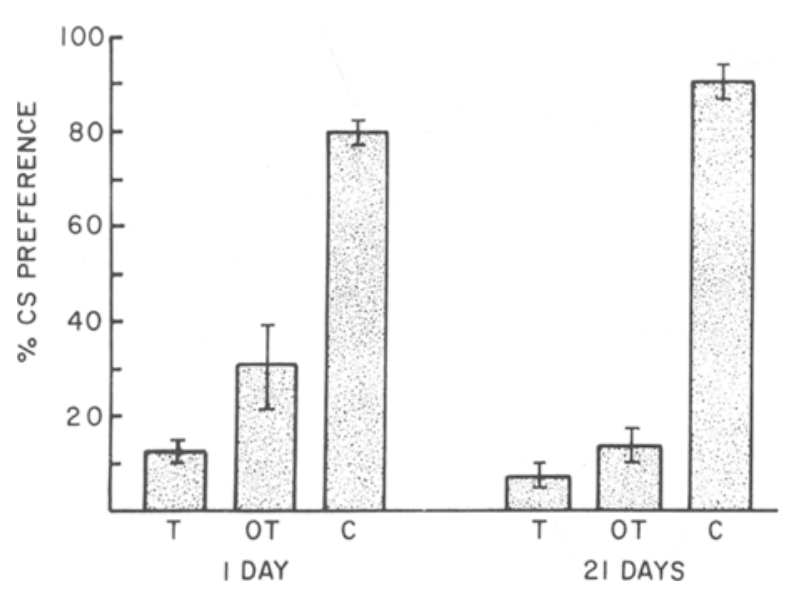

Figure 3. Percent chocolate milk preferences of adults in Experiment 2.

\section{Results and Discussion}

During conditioning, no differences in consumption were found among the groups. (Mean consumption for Groups T, OT, and C was $22.8,20.6$, and $20.0 \mathrm{ml}$, respectively.) Mean chocolate milk preferences during the retention tests are presented in Figure 3. Differences in preference strength can be seen as a function of conditioning experience and retention interval. A conditioning experience $\times$ retention interval analysis of variance was performed on these data. A significant main effect appeared for conditioning experience $[F(2,42)=187.5]$, and the conditioning experience $X$ retention interval was also significant $[F(2,42)=5.7]$. In order to clarify the nature of this interaction, separate analyses were conducted on the preference scores.

The data generally replicated those of Experiment 1. Preferences after the 1-day retention interval were significantly lower in Group $T$ than in Group OT, indicating overshadowing shortly after conditioning; preferences in both of these groups were significantly lower than in Group C. After the 21-day retention interval, preferences in Groups $\mathrm{T}$ and OT were equivalent and were lower than preferences in Group $\mathrm{C}$, indicating once again the dissipation of overshadowing over the relatively long interval, despite retention of conditioning.

These results indicate that after a 1 -day retention interval, odor had an attenuating effect on a conditioned taste aversion in these adult rats. This replicates the findings of Experiment 1. After a 21-day retention interval, the attenuating effect of odor was no longer evident, also as found in Experiment 1. Although the precise mechanism for these effects remains in question, it does seem clear that expression, rather than formation, of taste aversions is involved (Spear, 1981).

\section{GENERAL DISCUSSION}

The present experiments revealed an important influence of retention interval on taste aversions. Over- shadowing of a taste aversion by odor was obtained in adults tested after a 1-day retention interval but not after a 21-day interval, even though the taste aversion itself did not weaken during this longer interval. For adults conditioned with odor-taste compounds, expressed aversion to the taste increased over the 3-week retention interval. An important implication of this finding is that the overshadowing effect at the short retention interval may represent a retrieval failure effect, rather than the acquisition deficit typically assumed (Pavlov, 1927; Rescorla \& Wagner, 1972; Sutherland \& Mackintosh, 1971). Such a conclusion gains credence from recent research indicating that overshadowing can be ameliorated by postconditioning experiences (Kasprow, Cacheiro, Balaz, \& Miller, 1982; Kaufman \& Bolles, 1981; Matzel et al., 1985). The contention is that overshadowing may involve a disruption in the expression of learned experiences, as opposed to deficits in information storage (Miller et al., 1986; Spear, 1981).

There are alternative explanations for this effect. One possibility is that neophobia may have increased over the retention interval. If it is assumed that the group conditioned with taste alone was expressing the maximum aversion supportable by the conditioning parameters, then their aversions would not be expected to increase over the retention interval, whereas aversions in the group conditioned with an odor-taste compound may have increased, due to a general increase in neophobia over the delay. The fact that the saline control animals' preference scores were unchanged over the 21-day interval argues against the neophobia explanation. A more plausible alternative is that the generalization gradient for aversions to the odor-taste compound may have flattened over the retention interval (Thomas, 1981). This may have increased aversion strength for animals tested 21 days after conditioning. This alternative is not incompatible with the retrieval-failure hypothesis offered above.

These experiments also suggest important ontogenetic differences in the initial expression of a taste aversion conditioned to multielement stimuli. Experiment 1 replicated the reports of Kucharski and Spear (1985), Spear and Kucharski (1984a, 1984b), and Hinderliter and Misanin (1986) in showing that the conditioning of taste aversions in adults is attenuated by the presence of an odor during conditioning, whereas such conditioning in preweanlings is either unaffected or potentiated by such odors. These findings contrast with those of Peterson et al. (1985), who found that taste aversions in adults, but not in relatively old weanlings, were potentiated by odor. As discussed by Peterson et al., a number of methodological differences may be responsible for this discrepancy. It should be noted, however, that the incidence of weaning among the younger animals tested in these studies does not seem to be critical. Although Kucharski and Spear used preweanlings and Peterson et al. used weanlings, findings comparable to those of Kucharski and Spear were obtained in the present study, in which weanlings were used. 


\section{REFERENCES}

Bouton, M. E., \& Whiting, M. R. (1982). Simultaneous odor-taste and taste-taste compounds in poison-avoidance learning. Learning \& Motivation, 13, 472-494.

CAZA, P. A. (1984). Noradrenergic influences on blocking: Interactions with development. Pharmacology, Biochemistry \& Behavior, 21, 9-17.

Durlach, R. J., Rescorla, R. A. (1980). Potentiation rather than overshadowing in flavor-aversion learning: An analysis in terms of within-compound associations. Journal of Experimental Psychology: Animal Behavior Processes, 6, 175-187.

Hinderliter, C. F., \& Misanin, J. R. (1986, November). Weanling and senescent rats process compound conditional stimuli differently than young adults. Paper presented at the annual meeting of the International Society for Developmental Psychobiology, Annapolis, MD.

Kasprow, W. J., Cacheiro, H., Balaz, M. A., \& Miller, R. R. (1982). Reminder-induced recovery of associations to an overshadowed stimulus. Learning \& Motivation, 13, 155-166.

Kaufman, M. A., \& Bolles, R. C. (1981). A nonassociative aspect of overshadowing. Bulletin of the Psychonomic Society, 18, 319-320.

KEPPEL, G. (1982). Design and analysis: A researcher's handbook (2nd ed.). Englewood Cliffs, NJ: Prentice-Hall.

Kraemer, P. J., \& Roberts, W. A. (1984). The influence of flavor preexposure and test interval on conditioned taste aversions in the rat. Learning \& Motivation, 15, 259-278.

KucharSKI, D., \& SPEAR, N. E. (1985). Potentiation and overshadowing in preweanling and adult rats. Journal of Experimental Psychology: Animal Behavior Processes, 11, 15-34

LETT, B. T. (1980). Taste potentiates color-sickness associations in pigeons and quail. Animal Learning \& Behavior, 8, 193-198.

MACKINTOSH, N. J. (1975). A theory of attention: Variations in the associability of stimuli with reinforcement. Psychological Review, 82, 276-298.

Matzel, L. D., Schachtman, T. R., \& Miller, R. R. (1985). Recovery of an overshadowed association achieved by extinction of the overshadowing stimulus. Learning \& Motivation, 16, 398-412.

Mikulka, P. J., Pitts, E., \& Philput, C. (1982). Overshadowing not potentiation in taste aversion conditioning. Bulletin of the Psychonomic Society, 20, 101-104.

Miller, R. R., Kasprow, W. J., \& Schachtman, T. R. (1986).
Retrieval variability: Sources and consequences. American Journal of Psychology, 99, 145-218.

Pavlov, I. P. (1927). Conditioned reflexes (G. V. Anrep, Trans.). London: Oxford University Press.

Peterson, C. S., Valliere, W. Z., Misanin, J. R., \& Hinderliter, C. F. (1985). Age differences in the potentiation of taste aversion by odor cues. Physiological Psychology, 13, 103-106.

Rescorla, R. A., WAGNER, A. R. (1972). A theory of Pavlovian conditioning: Variations in the effectiveness of reinforcement. In A. H. Black \& W. F. Prokasy (Eds.), Classical conditioning II: Current research and theory (pp. 64-99). New York: Academic Press.

Rusiniak, K. W., Hankins, W. G., Garcia, J., \& BretT, L. P. (1979). Flavor-illness aversions: Potentiation of odor by taste in rats. $B e$ havioral \& Neural Biology, 25, 1-17.

Rusiniak, K. W., Palmerino, C. C., \& Garcia, J. (1982). Potentiation of odor by taste in rats: Tests of some nonassociative factors. Journal of Comparative \& Physiological Psychology, 96, 775-780.

SPEAR, N. E. (1981). Extending the domain of memory retrieval. In N. E. Spear \& R. R. Miller (Eds.), Information processing in animals: Memory mechanisms (pp. 341-378). Hillsdale, NJ: Eribaum.

SPEAR, N. E., \& KUChARSKI, D. (1984a). Ontogenetic differences in stimulus selection during conditioning. In R. V. Kail \& N. E. Spear (Eds.), Memory development: Comparative perspectives (pp. 227-252). Hillsdale, NJ: Erlbaum.

SPEAR, N. E., \& KucharSKI, D. (1984b). Ontogenetic differences in the processing of multi-element stimuli: Potentiation and overshadowing. In H. Roitblat, T. Bever, \& H. Terrace (Eds.), Animal cognition (pp. 545-568). Hillsdale, NJ: Erlbaum.

Sutherland, N. S., \& Mackintosh, N. J. (1971). Mechanisms of animal discrimination learning. New York: Academic Press.

Tномаs, D. R. (1981). Studies of long-term memory in the pigeon. In N. E. Spear \& R. R. Miller (Eds.), Information processing in animals: Memory mechanisms. Hillsdale, NJ: Erlbaum.

Westbrook, R. F., Homewood, J., Horn, K., \& Clarke, J. C. (1983). Flavour-odour compound conditioning: Odour-potentiation and flavour-attenuation. Quarterly Journal of Experimental Psychology, 35B, 13-33.

(Manuscript received April 10, 1987; revision accepted for publication September 22, 1987.) 